\title{
Assessing the awareness and adoptability of pellet cookstoves for low-income households in Lusaka, Zambia
}

\author{
Mukuka Mpundu Mulenga ${ }^{1}$ (D), Anders Roos ${ }^{\star 2}$ \\ 1. Department of Earth Sciences, Uppsala University, Uppsala, Sweden \\ 2. Department of Forest Economics, Swedish University of Agricultural Sciences, Uppsala, Sweden
}

\begin{abstract}
Wood fuel, charcoal, and firewood comprise over 70 percent of the national energy consumption in Zambia, as only about 25 percent of the population has access to electricity. Replacing charcoal braziers with cookstoves using sawdust pellets can support sustainable energy provision in urban Zambia while reducing deforestation on the countryside. However, acceptability of pellet cookstoves remains low, while the demand for wood fuel is increasing. The study investigated the acceptability of pellet cookstoves, in view of governmental policies, in the Matero-George compound, Lusaka. Qualitative approaches were applied, and respondents were households, Departments of Energy and Forestry, and Lusaka City Council. Factors shaping the stoves' acceptability included their convenience, possibility of reusing pellets, their long-term cost advantages, and the perceived health benefits of pellets. The barriers included limited supply of pellets, combustible pellet cookstoves, stove size, maintenance costs, cooking traditions, and government policies for dissemination, sensitisation, and communication about pellet stoves. This study demonstrated that implementation of pellet cookstoves at the local level depends on a multitude of contextual factors, and confirms the need for relevant policy instruments if such energy consumption is to be accepted.
\end{abstract}

Keywords: adoption, charcoal, pellet fuels, sustainable development, pellet cookstoves, wood fuel

\section{Highlights}

- Adoption of pellet cookstoves is slow.

- Acceptability is influenced by several user attributes and policies.

- Diffusion success requires a user-centred combination of interventions.

Journal of Energy in Southern Africa 32(3):-

DOI: https://dx.doi.org/10.17159/2413-3051/2021/v32i3a11463

Published by the University of Cape Town ISSN:2413-3051 https://journals.assaf.org.za/jesa

This work is licensed under a Creative Commons Attribution-ShareAlike 4.0 International Licence

Sponsored by the Department of Science and Innovation

Corresponding author: Tel.: +46 (0)73 984 0705; email: anders.roos@slu.se 


\section{Introduction}

The world's poor are continuously affected by the low availability of sustainable, reliable energy (Johnson and Bryden, 2012; Bailis et al., 2015; FAO 2017). Almost 2.6 billion people lack clean cooking facilities, and over 0.8 billion people have no access to electricity, 75 percent of whom live in Sub-Saharan Africa (IEA, 2020a). Consequently, there is a need for clean energy, as indicated by United $\mathrm{Na}$ tions Sustainable Development Goal number 7, which aims at securing sustainable energy for all (United Nations, 2015; Hanif, 2018).

Most Zambian households rely on wood fuel (firewood and charcoal) for cooking and heating (Republic of Zambia, 2019; IEA, 2020b). Charcoal and firewood make up over 70 percent of national energy consumption, which creates an increased pressure on forest resources (Republic of Zambia, 2019; FAO, 2020a; FAO, 2020b). Wood fuel causes indoor pollution and affects people's health, especially women's and children's (Hanif, 2018). Therefore, the Zambian government and private and nongovernmental organisations are promoting policies and initiatives for accessing sustainable, reliable clean energy, such as pellet stoves (KachapululaMudenda et al., 2018).

Globally, improved cooking stoves (ICS) have been promoted in regions with high biomass use to reduce the demand for wood fuel and related indoor air pollution. Private and government actors have been involved in efforts that include research and development, testing, and monitoring (Bailis et al., 2009; Kshirsagar and Kalamkar 2014). Although ICS and clean fuels designed to reduce air pollution are available, their adoption is a challenge, and the success of ICS campaigns has been mixed (Bailis et al., 2017). Adoption of ICS remains low, while the demand for fuelwood is high (Kulindwa et al., 2018). Hence, there is a need to find and understand the drivers and barriers to adoption of ICS. Research has identified several success factors, including costs (Bailis et al., 2009; Atteridge 2013), stove flexibility (Kulindwa et al., 2018), and knowledge (Kulindwa, 2018; Seguin et al., 2018). However, more understanding about influences on adoption is needed, especially on contextual factors such as use operations and incentive structure (Ruiz-Mercado et al., 2011, Lewis and Pattanayak 2012). To understand ICS diffusion in domestic energy usage (Peša, 2017), a situated approach that encompasses contextual aspects that may not surface in an ordinary survey is required (Polanyi, 1958; van Kleef et al., 2005, Rogers, 2003). Further research should also investigate user perceptions and government policies for diffusing stove use (Ruiz-Mercado et al., 2011; Lewis and Pattanayak 2012).

This study aimed to assess the acceptability of the pellet cookstoves in Lusaka, Zambia in view of government policies. The research included four research questions:

1. What combination of factors influences households' preference and choice of braziers or pellet cookstoves?

2. What challenges do households face in relation to their current cooking solutions and the options available to them?

3. What knowledge do households have about available energy options, their sustainability impacts, and their levels of cleanliness?

4. How effective are governmental policies and strategies in promoting new cooking technologies, especially pellet cookstoves?

\section{Materials and methods}

\subsection{Conceptual framework}

The conceptual framework for this study draws on theories on diffusion of innovations, sustainable livelihoods, and sustainability transition. Diffusion of innovations explains how adoption of innovations depends on the adopter's financial capacity, the accessibility of benefits that lie within the innovation, and the socioeconomic status of the system in which diffusion is taking place (Rogers, 2003; Rehfuess et al., 2014). According to Rogers (2003), key parameters for adoption success, such as ICS for wood pellets, involve relative advantage, compatibility with existing practices, complexity, trialability, and observability. The sustainable livelihoods framework involves achieving sustainability and households' standards of living (DFID, 1999). In this study, it focuses on livelihoods' impacts based on five parameters: vulnerability context, livelihood assets, transforming structures and processes, livelihood strategies, and livelihood outcomes. Models of policy and sustainability transitions help explain how policy mixes influence socio-technical change (e.g. adoption of pellet cookstoves) and how changes in the socio-technical system use feedback loops to shape policy evolution. It is assumed that policy mixes aiming to foster sustainability transitions such as adoption of pellet cookstoves, should be designed to create incentives for beneficiaries to mobilise further policy support (Edmondson et al., 2019).

\subsection{Methods}

\section{The case: Pellet stoves in Lusaka}

This research was based on the LuMa Sustainable Energy project, a partnership between Malmö Municipality (Sweden) and the Lusaka City Council, which began in 2007 (ICLD, 2021). It aimed to reduce inefficient and unhealthy charcoal use while also reducing the impact on the forest environment. Pellets were processed from sawdust waste in the Copperbelt. Pellet cookstoves can replace the charcoal braziers that have dominated home usage since 
the 1930s, and thereby reduce indoor pollution (Peša, 2017). A charcoal brazier can be seen in Figure 1, and Figure 2 shows charcoal repackaged in smaller sizes for resale.

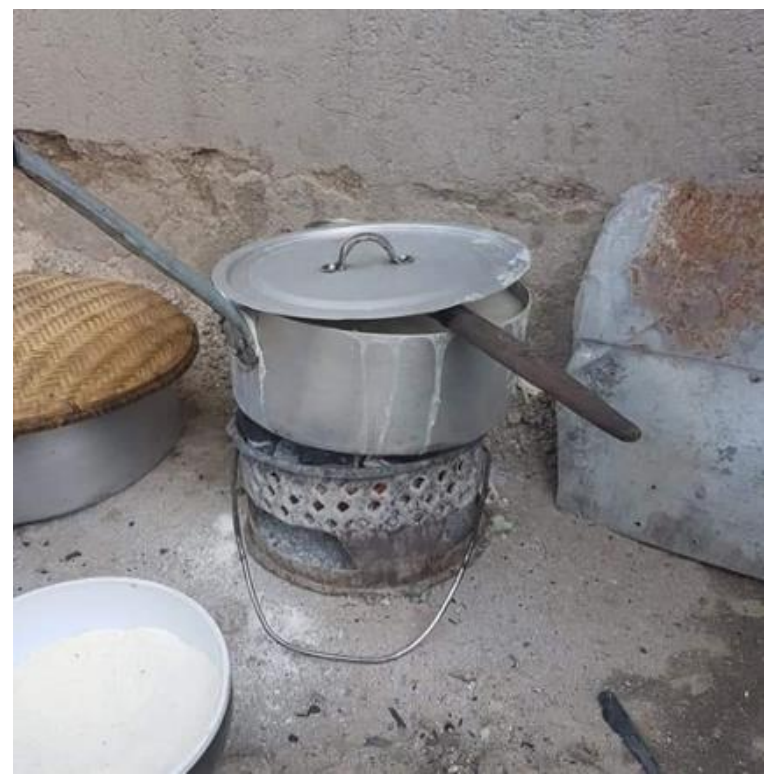

Figure 1: Charcoal brazier (stove-mbabula). Source: Picture taken by researcher

Braziers are used to burn charcoal for cooking and heating, and are perforated to allow combustion. Charcoal is placed on the plate and lit, and the elevation helps circulate air to feed oxygen to the fire. As the charcoal burns, both the fire and charcoal reduce, creating ashes; more charcoal must be added to make the fire grow again.

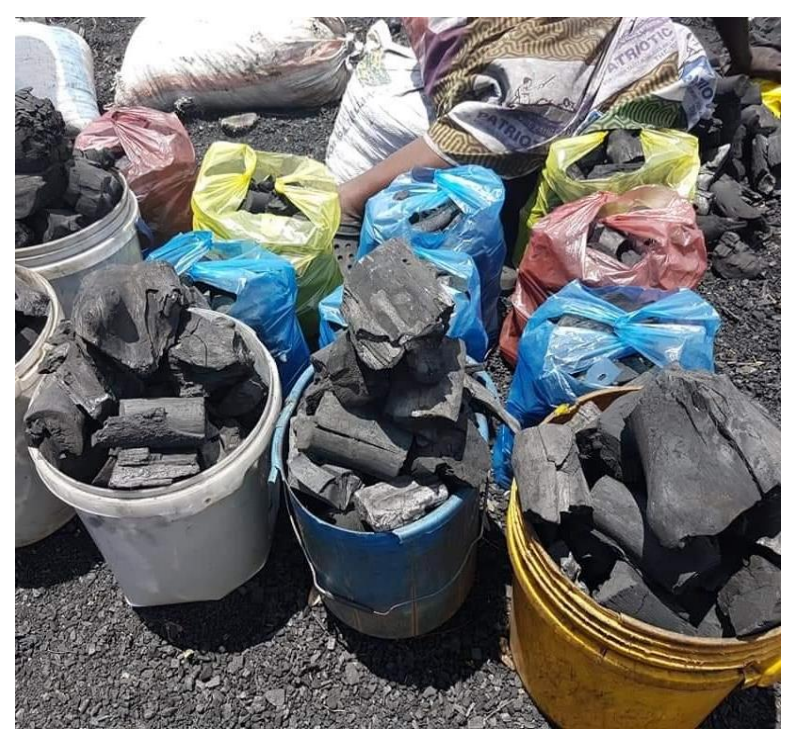

Figure 2: Charcoal repackaged in smaller packages for resale.

Source: Picture taken by researcher

Figures 3 and 4 show the pellet cookstove and its handling. The fuel pellets can be seen in Figure 5 .

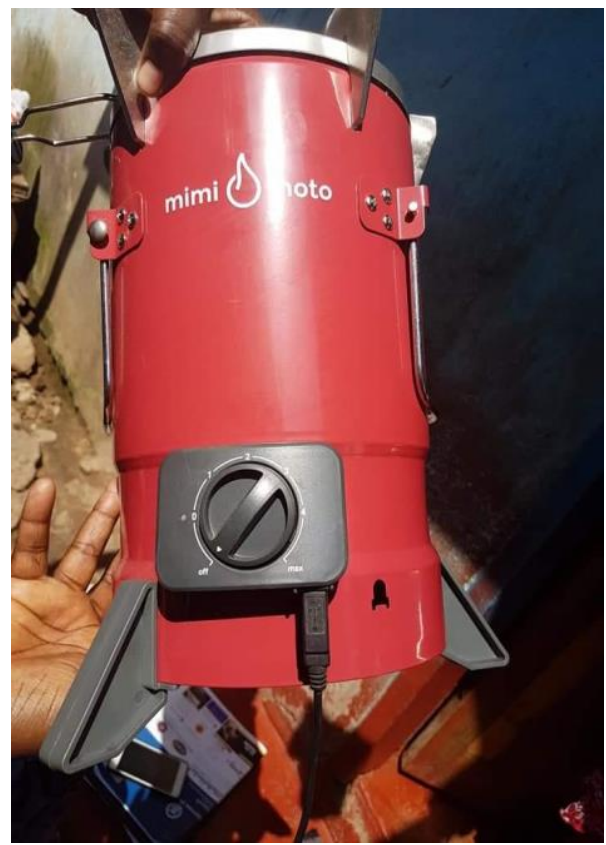

Figure 3: Pellet cookstove.

Source: Picture taken by researcher

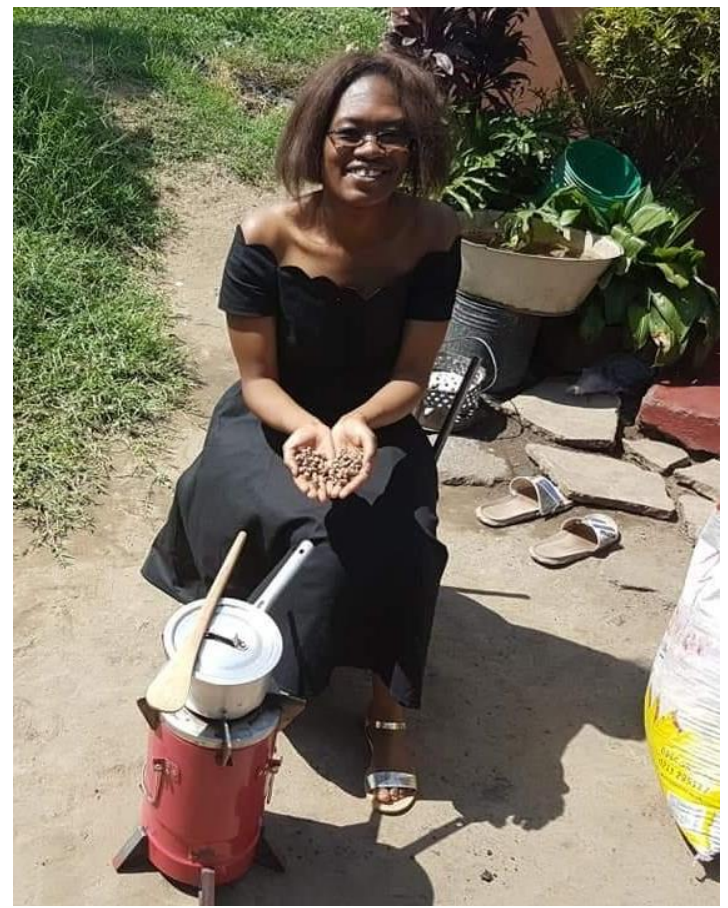

Figure 4. Researcher using a pellet cookstove and sawdust pellets.

The pellet cookstove burns sawdust pellets for cooking and heating, and a fan circulates air to allow combustion. Pellets are placed into the combustion pot and lit. As the pellets burn, the fire reduces and the pellets turn into ashes. The ashes fall into an ash pan that can be emptied when full. After the fire in the stove is extinguished, it can be relit using the pellets inside that were not previously consumed, and does not necessarily need to have more fuel 
added. The stove has a dual battery charging system, that is, through a solar panel or electricity, and it can only be used when the battery is charged.

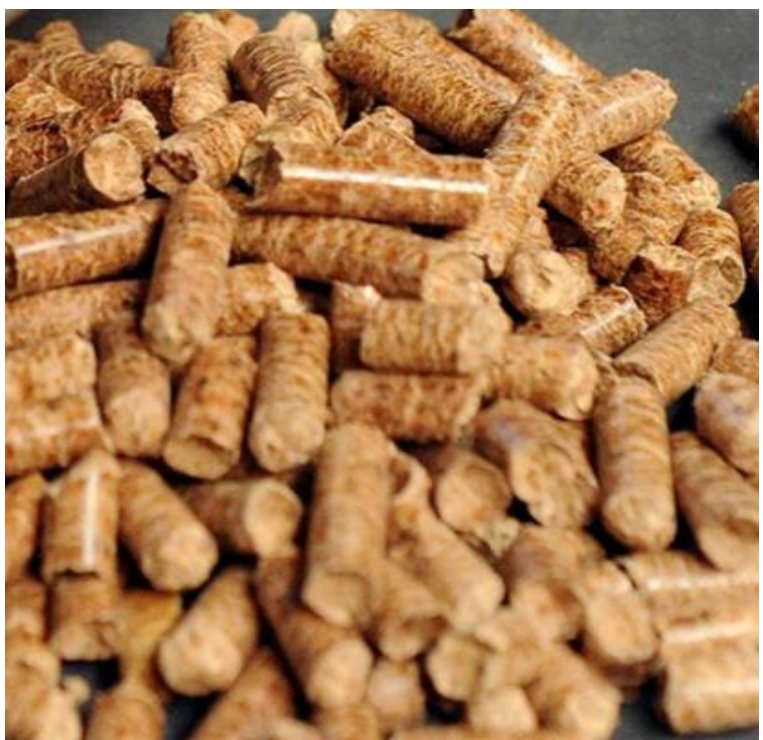

Figure 5: Pellets.

Source: Picture taken by researcher

\section{Research approach}

Due to the holistic nature of the study, a qualitative study approach was used to understand users' perceptions, practices, preferences and expectation. Interviews and focus group discussions with household representatives were conducted and complemented with interviews with municipal and government officers. Documents describing energy, forests, and the dissemination project were analysed to identify the project timeline and its effectiveness (Government of Zambia 2008, 2009, 2011, 2014a, 2014b, 2015a, 2015b, 2017). The interview data covered energy use, stove type, experiences, advantages, and disadvantages in using different energy options, as summarised in Table 1.

The community sample comprised fifteen lowincome households of Matero-George Compound of Lusaka, which had received and used the pellet cookstoves through the LuMa project; and five randomly selected low-income households that did not receive the pellet cookstoves (non-beneficiaries). Respondents were fifteen females and five males (Table 2). The sample of government and municipal officials consisted of five respondents from the Lusaka City Council, (Implementing Agency of the LuMa project), three officials in the Zambia Department of Energy, and two government officers at the Department of Forestry. The municipal and government officers were selected based on having job descriptions in line with the study, so they were in positions to provide the in-depth information that was required in the study (Table 2). Semi-structured interviews and focus group discussions were conducted. The interviews lasted between one to two hours for all the participants, and were recorded using a voice recorder.

\section{Table 1. Summary of questions in interview guides/questionnaires}

\begin{tabular}{ll} 
Respondents & \multicolumn{1}{c}{ Questions/topics } \\
$\begin{array}{l}\text { Household } \\
\text { interviews } \\
\text { and focus } \\
\text { groups }\end{array}$ & $\begin{array}{l}\text { Household energy use } \\
\text { rent, charcoal, electricity }\end{array}$ \\
& $\begin{array}{l}\text { Knowledge and attitude towards } \\
\text { pellet stoves }\end{array}$ \\
& Information about stove use \\
& Factors influencing fuel selection \\
& Economics of household energy \\
& Barriers for adopting pellet \\
stoves \\
Interviews \\
with munic- \\
ipal and \\
government \\
officers & ICS. \\
& $\begin{array}{l}\text { Policies' impact on household en- } \\
\text { ergy use } \\
\text { for medium- and high-income }\end{array}$ \\
& households \\
& Processes in the fuel value chain. \\
& Collaboration between govern- \\
& ment bodies. \\
& $\begin{array}{l}\text { Available subsidies for ICS adop- } \\
\text { tion. }\end{array}$ \\
& $\begin{array}{l}\text { Population's attitudes towards } \\
\text { ICS }\end{array}$ \\
&
\end{tabular}

The interviews with local community members were conducted at their homes, in two local languages (Bemba and Nyanja) that both the first author and the participants were familiar with. This created trust and enabled the researcher to ask relevant follow-up questions and apprehend nuances in the answers. Government officers were interviewed in English at their ministry offices. The interviews and focus group discussions lasted for 1-2 hours. Notes were taken, and some interviews were recorded and the data transcribed for analysis. The analysis consisted of making sense of the of the participants' definitions of the situation and noting patterns, themes, categories, and regularities (Cohen et al., 2011; Miles and Huberman, 1994). The fieldwork and study approaches followed the principles of informed consent, privacy and confidentiality (Swedish Research Council, 2017). 
Table 2: List of institutions and households interviewed

\begin{tabular}{|c|c|c|c|}
\hline Interviewees & Topic & $\begin{array}{l}\text { Number of } \\
\text { respondents }\end{array}$ & Interview type \\
\hline Households & $\begin{array}{l}\text { Beneficiaries of pellet } \\
\text { cookstoves }\end{array}$ & 15 & $\begin{array}{l}\text { Individual or focus } \\
\text { group }\end{array}$ \\
\hline Households & $\begin{array}{l}\text { Non-beneficiaries of pellet } \\
\text { cookstoves }\end{array}$ & 5 & $\begin{array}{l}\text { Individual or focus } \\
\text { group }\end{array}$ \\
\hline Lusaka City Council & Implementing agency & 5 & Individual \\
\hline Department of Energy & Government officers & 3 & Individual \\
\hline Department of Forestry & Government officers & 2 & Individual \\
\hline
\end{tabular}

\section{Results}

\subsection{Factors shaping acceptability of pellet cookstoves \\ Convenience}

The interviewees indicated that the pellet cookstove had several convenience advantages: It was light and cooked food faster, similar to a gas or electrical stove. They also liked that it could be charged using electricity or solar energy (in case of power outages). The pellet stoves are not affected by wind and do not emit heat when cooking, unlike a charcoal brazier, due to differences in the way they are made. Further, households lauded the fan that helped light the fire, instead of the external hollow pipe a charcoal brazier requires. A knob enables users to adjust and regulate the heat, and the fuel consumption is lower than that for a charcoal brazier. Respondents reported that, even after repeated uses, hands and pots remained clean - when using charcoal braziers, hands and pots become darkened and difficult to clean or wash. Once one dish was finished cooking, the next dish could follow without any additional load of pellets. One respondent said:

For pellet cookstoves, if the knob setting is put on the highest, you can cook many or more dishes using one load of pellets, whereas for charcoal you need to replenish with a number of loads to cook a similar dish, and it is an inconvenience. (Respondent 1, 2019)

This shows how some households thought the pellet cookstoves were convenient, especially when it came to replenishing when cooking. These convenience aspects made the pellet stove comparable with electric stoves, which are also quick to light. However, there are frequent power cuts, which makes electric stoves less reliable.

Reuse

Users noted that pellets could be reused after putting out the fire. This differentiates the stove from charcoal, which had to be extinguished with water. The charcoal would become wet and not reusable.
Pellets also produce less ash than charcoal. A respondent said:

Charcoal is difficult to light when you put out the fire with water. It is also scarce in the rainy season and is mostly wet and more expensive. Pellet cookstoves, on the other hand, work with solar energy to charge (in case of a power cut), as they have a solar panel and they produce its own air with a fan made in it. It is not affected when the wind blows, as the case with charcoal braziers, and you just switch it on as you please. It also has a fan and you can regulate it. (Respondent 2, 2019).

Households mentioned that they could not cook on electrical stoves because they were not connected to the national electricity grid. Some households indicated they cared about being able to reuse the pellets even after they had been out, which they felt was economical.

\section{Pellet stoves are cheap in the long term}

Different forms of energy have different economic implications. According to respondents, electricity is more expensive than charcoal and pellets. Pellet stoves were considered cheaper in the long run due to having a lower fuel requirement than charcoal braziers. However, pellet stoves are expensive to purchase. One respondent said:

I usually use three 50-kilogram bags of charcoal per month, compared to a pellet cookstove, where an entire pack of pellets is used for a month and is only 45 Kwacha (USD 2.00) compared to 300 Kwacha (USD 13.50) for charcoal. The price of charcoal has increased abnormally, especially that it is seasonal. Both during the rainy season and cold season it is ridiculously expensive because people travel long distances to produce the charcoal, and bad roads and fuel for transportation has led to the hike in charcoal. The pellet cookstove is also very expensive, going for 1400 Kwacha (USD 63). I could not buy the stove if I had not been given one; it 
is too expensive, even if I could pay in instalments. It is just not affordable. (Respondent 3 , 2019).

\section{Health aspects}

The sawdust-pellet stove was reckoned as healthier and less polluting when compared with charcoal, allowing for indoor cooking.

Charcoal usage causes lesions/cuts in the hands with continuous touching and breaking the charcoal when placing on a brazier. There are risks with burns, and it emits smoke. It also makes hands and pots dirty, unlike pellets. Smoke from charcoal intoxicates and causes suffocation, and you cannot sleep with a brazier in the house, as it causes headaches. It is only good for outdoor cooking, different from pellet cookstoves. (Respondent 4, 2019).

Charcoal, together with fuelwood, was reported to be the least healthy fuel, since it could cause respiratory problems, coughing, headaches, and even death from carbon monoxide exposure. Respondents alluded to the fact that, unlike the charcoal brazier, the pellet cookstove had no perforations emitting carbon monoxide, as it produced its own air using the internal fan. Pellet cookstoves (like the electric stove) were considered to be clean and suitable for indoor or enclosure cooking. Here is a remark from one respondent:

Pellet cookstoves don't produce smoke that causes coughs. They can be used in indoor cooking, without intoxication. You can cook indoors with the pellet stove, unlike charcoal braziers that can be problematic in the rainy season as you cannot cook inside, despite rains. Cooking on a pellet stove does not give headaches and dizziness, like charcoal. It does not have holes like charcoal brazier, and can be used indoors. (Respondent 5, 2019)

\subsection{Factors hindering uptake of pellet cookstoves Disadvantages with pellet fuel}

One barrier to adoption was that pellets are manufactured in one main source in the Copperbelt province of Zambia, which makes the supply less reliable. Pellets are not readily available, unlike charcoal/firewood (although these latter fuels were also scarce in the rainy and cold seasons). Further, respondents reported that pellets were loaded only once, because replenishment extinguished the fire; further pellets could not be added until the current pellets were fully consumed. This meant putting another load of pellets in the combustion pot and restarting the process of lighting the fire, and some respondents thought this was an inconvenience and a cumbersome process. One respondent said:
One barrier with the pellets, you can only load once in the stove when cooking, and so when the burning pellets finish, you cannot add further pellets and continue cooking, as is the case with charcoal, which can be replenished throughout the cooking process. Pellet cookstoves and pellets are not easily accessible, which is a disadvantage, and it cannot be used to cook certain foodstuffs, for instance roasting meat. (Respondent 6, 2019)

Some households felt that the limited supply of pellets, inaccessibility, and the whole process of lighting the fire when the burning load finished was cumbersome.

\section{Pellet cookstoves were highly combustible}

Households also stated that pellet cookstoves were highly combustible and sometimes burnt the food if not regularly checked, despite having a regulator. Two respondents complained that the hard flame from the pellet stove created holes in the bottom of the pot. One of them said:

My pot got a hole in the middle where heat from the stove was concentrated. The pellet stove should be designed in such a way that heat is distributed to the entire bottom of the pot, unlike the concentrated heat on the central bottom rendering damage / holes to the pot. Also, to counter this damage to the pots, the stoves' manufacturers should introduce different pots with different metals suitable for the heat. (Respondent 7, 2019)

\section{Pellet stove not big enough for some families}

Yet another drawback was the size of the stove. Larger families, institutions, and schools need big stoves. In these cases, the pots could not fit on the pellet stoves, and charcoal had to be used to cater for many people. Also, pellet cookstoves could not be used to prepare different dishes simultaneously. A respondent reported that:

If the pot is very big, you cannot cook on the pellet cookstove. A bigger pellet cookstove, as opposed to the current ones manufactured, would make more sense to cook for big families and public institutions like the school where I am teaching. Important considerations in manufacturing the pellet stove should be made. (Respondent 8, 2019)

Some households furthermore complained that pellet stoves lacked features such as an oven.

\section{Repairing a pellet stove not easy}

Repairing a pellet stove requires specialised expertise, as opposed to a charcoal brazier that can easily be fabricated with metal, repaired, and replaced by 
tinsmiths at local markets or workshops. Respondents reported that, although they were told by the manufacturer that the pellet cookstove had a lifespan of about ten years, problems such as malfunctioning or damage often occurred much earlier. The interviewees deplored the delicacy of the pellet cookstove, saying it needed caution and care to avoid spilling any water or oil its battery, which resulted in damaged stoves and repairs. One respondent pointed out that:

You need to clean the pellet cookstove just like an electrical stove, and you do not need to spill water on it as it can damage the stove (and battery). You must follow instructions when using it, and, if you are poor at instructions, you will find it difficult to use. If you do not know how to operate it, you can easily damage the stove and, hence, you need to understand its usage. What is even more challenging is first-time operation of the pellet stove, as it is quite difficult, but becomes easier after you get acclimatised to its operation. (Respondent 9, 2019)

Pellet cookstoves cannot be used to cook some foods Households further pointed out that pellet cookstoves, unlike charcoal braziers, could not be used to cook certain foods, such as roasting meat, because this would put out the fire. It was mainly mentioned that cooking on a charcoal brazier gave good warmth, great taste, flavour, aroma, and savour to the food. Also, in cases with both interrupted electricity and no sunlight, it was not possible to charge the battery, meaning that the pellet stove could not be used. However, a few households applauded the pellet stove for being able to cook for as long as one month once it was fully charged, without being recharged, because the battery drained slowly if used at a lower temperature (between 0 and 1 on the regulating knob).

\section{Public support}

Lack of government policy instruments regarding dissemination, sensitisation, and communication strategies about the new cookstoves also affects the adoption process. A respondent explained that:

Policy instruments don't have any policy talking specifically about new cookstoves, but, in the process of developing energy-efficiency strategies, look into new cookstoves and energy efficient lighting. The instruments on new cookstoves are non-existent. Since they do not have policy specifically on new cookstoves, they do not have strategies to disseminate and sensitise on them. The energy policy looks into efficient energy use, for instance, efficient use of wood fuel and efficient charcoal production. Strategies are being developed at the moment, and that is where there are gaps in the energy sector. There have been challenges with identifying the gaps from electricity usage, wood fuel usage and charcoal usage; hence, the reason for currently developing strategies to address those gaps. (Respondent 10, 2019)

It was evident that there was a lack of supportive government policy instruments, although improving adoption of pellet cookstoves requires addressing barriers relating to dissemination, sensitisation, and communication.

\subsection{Government officials' view}

According to government officials, the use of forest resources is regulated and anchored among stakeholders. Conversely, there are few policy instruments specifically targeting cookstoves. Few policy instruments were introduced for the dissemination of ICS. Government officials that were interviewed indicated that communication and sensitisation efforts were needed to inform communities about the existence of cleaner stoves. Most officials confirmed the households' claims that alternatives to charcoal were too expensive for the locals, as they were not subsidised. It was pointed out that usually when most ICS were introduced after a year or so they disappeared, because they did not meet households' needs. Officials believed that the stoves had to be made locally, like charcoal braziers, to succeed.

When asked whether policies and strategies currently being implemented were appropriate for households to switch to alternatives fuels, a respondent (an official) answered:

In most instances, households are given these alternatives (stoves) for free as a pilot study, but once the project or pilot is ended, they switch to their previously-used energy and pack the alternative stoves given to them. Most people in middle- and low-income households live hand-to-mouth such that even a small amount, such as 50 kwacha (USD 2), is hard to come by. Everything is given for free whilst the project is running and fails to continue at the end of the project. (Informant 1, 2019)

Another respondent pointed out that charcoal, unlike pellets, was readily available in large bags, or repackaged in small plastic bags (Figure 2) that were cheap. Only well-off people would be able to afford the alternative pellet cookstoves. Hence, it was important to look into charcoal users' economic situation and their ability to pay the up-front cost of a pellet stove. The respondent pointed out that 'Seventy percent of energy comes from wood fuel energy, and it is the consumer's primary energy. 
Therefore, the charcoal usage could not be banned and it was there to stay, unfortunately, whether we liked it or not.' The responded further said that "In some areas, such as typical rural areas, it is impossible to ban charcoal unless an alternative solution that people adopt instantly is provided. But it is impossible to implement that huge jump because it has to be cost effective." (Informant 2, 2019).

One respondent pointed out that she had a pellet cookstove and sometimes used it to cook. She said the pellet cookstove is designed with a battery charging system and required the stove to be charged before usage. It could not work if it were not charged, unlike a charcoal brazier which did not need a charging process. It was highlighted that the technologies behind these stoves were designed abroad. For instance, the pellet cookstoves could not be suitable for local households, as they did not have local end users in mind when they manufactured those stoves.

Government officials furthermore believed that diffusion campaigns were not well designed; a better way would be to market pellets and pellet stoves through the existing network of charcoal traders. Officers argued that households should have a range of fuels to choose among: briquettes, LPG, biogas, rice husks, and forest / agriculture waste.

Additionally, another respondent claimed that the underlying cause of deforestation was poverty, and that the fight against deforestation was not being won because of the following factors:

Lack of improved technology for charcoal production and utilisation of wood fuel, lack of training for charcoal producers in better organisation and management of charcoal production using the kiln method, lack of eagerness to adopt other production techniques which are more efficient and convenient to users and which produce minimal emissions, lack of participation of various stakeholders, such as women's clubs and cooperatives, as well as other government departments. (Informant 3, 2019).

One respondent said that charcoal was being demonised and blamed for deforestation, when there were many other causes. It was pointed out that the main causes of deforestation were agriculture expansion and infrastructural development, whilst charcoal production was named as the fourth cause.

\section{Discussion}

This study has shown that some households appreciate the pellet cookstove because it is hygienic, clean, cooks food quickly, is suitable for indoor and enclosure cooking, is easy to light, is durable, and does not emit smoke. Drawbacks concern fuel availability, purchase price, and handling and mainte- nance. This may point to why some beneficiaries were still cooking on charcoal braziers (Figure 1), despite possessing the pellet cookstoves.

The findings show that, with the current price of 1400 Kwacha (USD 63), despite subsidies and financing mechanisms, it is almost impossible for low-income households to afford the stoves, except for the current beneficiaries of the pilot project.

The appreciation of pellet stoves' cleanliness conforms to earlier results by Peša (2017). The favourable experiences of pellet stoves were similar to the findings of Jagger and Das (2018) for Rwanda. Reported drawbacks encompassing difficulties with the pellet fuel, impact on pots, price, and maintenance needs of the stove confirm similar findings by Atteridge (2013).

The findings are in line with previous adoption studies (Bailis et al., 2009; Atteridge 2013; Kulindwa et al., 2018; Seguin et al., 2018), as well as recounting diffusion of innovation theory (Rogers 2003). Irrespective of its advantages, the pellet cookstove was seen to be more expensive than the charcoal brazier. Hence, dependency on charcoal is linked to poverty and/or material deprivation (Rogers, 2003). This is true despite the developers marketing the technology to low-income households by claiming environmental, health and financial benefits upon adoption (Peša, 2017). It is important to note that low-income households' purchasing power was 'now' and not 'futuristic'. This was evidenced by these households' purchasing smaller packages of charcoal in plastic bags (Figure 2), which translated to paying a higher price per kilogram in aggregate terms, whilst wealthier households purchased larger quantities for a lower price per kilogram (Peša, 2017; Atteridge et al. 2013). Consequently, these same households are unlikely to invest in ICS for long-term benefits.

The complexity of charcoal use and the poverty nexus calls for multifaceted and integrated approaches on both the production and demand sides, to diffuse cleaner cooking options. Current policies are inadequate to address the challenge of reliable wood fuel production and supply and poverty reduction. Therefore, careful thought on promoting pro-poor and sustainability charcoal policies coordinated amongst various departments, including forestry, energy, water, and municipalities, is needed. Structural inequities and the incapacity to implement charcoal policy/cookstove policy and sustainable wood-fuel production need to be addressed.

This study has some limitations because it was confined to 20 households, targeting a few urban, high-density low-income households in informal employment, whose occupations involve vocational jobs such as carpentry. The study is most relevant for low-income urban households in Zambia. The 
rural situation may be different. The research did not target commercial consumers and business institutions, such as restaurants. The study's purpose was to capture different contextual factors for adoption - it is not a representative study.

\section{Conclusion}

This research sought to assess the levels of awareness, adoptability, and sustainability of pellet cookstoves in view of government policies using a user-centred approach in Matero-George compound, Lusaka. The analysis was guided by sustainable livelihoods, sustainable transitions, and diffusion of innovations theories. The results suggest that the awareness levels about pellet cookstoves were low due to the lack of sensitisation, dissemination, and communication strategies, a lack caused by the absence of coherent policy instruments on cookstoves. The findings indicate that reducing household dependency on charcoal needs coordinated, multifaceted policies for the dissemination of new cooking technologies and provision of affordable and user-friendly alternative energy sources for peri-urban households. The adoption of the pellet cookstoves was attributed to its convenience, cleanliness, reusability of pellets, health aspects, affordability, availability of crucial fuels (i.e. pellets), cultural norms, awareness/sensitisation levels, the low cost of competing charcoal braziers (mbabula), and usability and efficiency drawbacks of the cookstove.

The limitations of the pellet stove depended on its high combustibility, small size, need for delicate handling, its inability to cook food such as roasting meat, its initial high cost and the scarcity of pellets. Therefore, the motivation to switch to alternative fuels such as the pellet cookstoves could include incentives such as subsiding the new technologies to reduce their price, increasing the availability of pellets, and widespread sensitisation and awareness campaigns. Hence, several measures are needed to facilitate cleaner cooking solutions. End-users of the pellet stove should also be consulted when the stoves are designed. Involving the users in the stove manufacturing would disseminate the pellet stove on a larger scale and lead to its eventual adoption in more households. Users should also be included in the development team when prototype pellet stoves are developed, to capture aspects that influence acceptance. This would increase the adoption of cleaner cooking solutions with fewer environmental impacts attributed to deforestation.

\section{Author contributions}

Mukuka Mpundu Mulenga: Conceptualisation; Data curation; formal analysis; funding acquisition; investigation; methodology; project administration; resources; software; supervision; validation; visualisation; roles/writing - original draft; writing - review \&editing.

Anders Roos: Conceptualisation; Data curation; formal analysis; funding acquisition; investigation; methodology; project administration; resources; software; supervision; validation; visualization; roles/writing - original draft; writing - review and editing.

\section{Acknowledgements}

The study was financed by the Swedish Institute Scholarships for Global Professionals and carried out under the Sustainable Development Programme at Uppsala University. The Swedish International Centre for Local Democracy supported the fieldwork and beneficial advice was provided by Dr Camilla Widmark of Swedish University of Agricultural Sciences.

The authors also express gratitude to the Zambian government for making this study possible. A special tribute goes to all the participants from Matero-George Compound, and the government officers from the Lusaka City Council and Departments of Energy and Forestry for providing pertinent information, without which the dissertation from which the paper is drawn could not have materialised.

\section{References}

Atteridge, A., Heneen, M. and Senyagwa, J. 2013. Transforming household energy practices among charcoal users in Lusaka, Zambia: A user-centred approach. Stockholm Environment Institute Working Paper No 2013-04.

Bailis, R., Cowan, A. and Masera, 0. 2009. Arresting the killer in the kitchen: The promises and pitfalls of commercializing cookstoves. World Development 37: 1694-1705. DOI: https://doi.org/10.1016/j.worlddev.2009.03.004

Bailis, R., Drigo, R., Ghilardi, A. and Masera, 0. 2015. The carbon footprint of traditional woodfuels. Nature Climate Change 5: 266-272. DOI: https://doi.org/10.1038/nclimate2491

Bailis, R., Wang, Y. T., Drigo, R., Ghilardi, A. and Masera, O. 2017. Getting the numbers right: Revisiting woodfuel sustainability in the developing world. Environmental Research Letters 12.

Cohen, L., Manion, L. and Morrison, K. 2011. Research methods in education (7th ed.). London: Routledge.

DFID [Department for International Development]. 1999. Framework of sustainable livelihoods. Department for International Development, UK.

Edmondson, D.L., Kern, F., and Rogge, K.S. 2019. The co-evolution of policy mixes and socio-technical systems: Towards a conceptual framework of policy mix feedback in sustainability transitions. Research Policy 48(10). DOI: https://doi.org/10.1016/j.respol.2018.03.010

FAO [Food and Agriculture Organisation]. 2017. The charcoal transition: greening the charcoal value chain to mitigate climate change and improve local livelihoods, by J. van Dam. Rome: Food and Agriculture Organisation of the United Nations. 
FAO, 2020a. FAOSTAT- Forestry production and trade. Rome: Food and Agriculture Organisation of the United Nations. http://www.fao.org/faostat/en/\#data/FO (accessed January 4, 2021)

FAO, 2020b. Global forest resources assessment 2020 - Main report. Rome: Food and Agriculture Organisation of the United Nations.

Government of Zambia. 2008. National Energy Policy. Lusaka: Ministry of Energy and Water Development.

Government of Zambia. 2009. National Policy on Environment. Lusaka: National Assembly of Zambia.

Government of Zambia. 2011. Environmental Management Act. Lusaka: National Assembly of Zambia.

Government of Zambia. 2014a. National Forestry Policy. Lusaka: Ministry of Tourism, environment and natural resources.

Government of Zambia. 2014b. Energy regulation Act. Lusaka: National Assembly of Zambia.

Government of Zambia. 2015a. Forest Act. Lusaka: National Assembly of Parliament

Government of Zambia. 2015b. National strategy to reduce deforestation and forest degradation. Lusaka: Ministry of Lands and Natural Resources.

Government of Zambia. 2017. National policy on climate change. Lusaka: Policy monitoring and research centres.

Hanif, I. 2018. Energy consumption habits and human health nexus in Sub-Saharan Africa. Environmental Science and Pollution Research 25: 21701-21712. doi: 10.1007/s11356-018-2336-0.

ICLD, 2021. LuMa Sustainable Energy. Visby, Sweden: Swedish International Centre for Local Democracy. https://icld.se/partnership/kp-luma-sustainable-energy/ (accessed January 4, 2021)

IEA 2020a. SDG7: Data and projections. Paris: International Energy Agency. https://www.iea.org/reports/sdg7-dataand-projections (accessed August 15, 2021)

IEA 2020b. Zambia - Country profile. Paris: International Energy Agency. https://www.iea.org/countries/zambia (accessed December 15, 2020)

Jagger, P. and Das, I. 2018. Implementation and scale-up of a biomass pellet and improved cookstove enterprise in Rwanda. Energy for Sustainable Development 46: 32-41.

Johnson, N. G. and Bryden, K. M. 2012. Factors affecting fuelwood consumption in household cookstoves in an isolated rural West African village. Energy 46: 310-321. DOI: https://doi.org/10.1016/j.energy.2012.08.019

Kachapulula-Mudenda, P., Makashini, L., Malama, A. and Abanda, H., 2018. Review of renewable energy technologies in Zambian households: Capacities and barriers affecting successful deployment. Buildings 8, 77.

Kshirsagar, M.P. and Kalamkar, V.R. 2014. A comprehensive review on biomass cookstoves and a systematic approach for modern cookstove design. Renewable \& Sustainable Energy Reviews 30: 580-603. https://doi.org/10.1016/j.rser.2013.10.039

Kulindwa, J., Lokina, R. and Ahlgren, E. O. 2018. Driving forces for households' adoption of improved cooking stoves in rural Tanzania. Energy Strategy Reviews 20: 102-112. https://doi.org/10.1016/j.esr.2017.12.005

Lewis, J.J. and Pattanayak, S.K. 2012. Who adopts improved fuels and cookstoves? A systematic review. Environmental Health Perspectives 120: 637-645. doi: 10.1289/ehp.1104194

Miles, M.B. and Huberman, A.M. 1994. Qualitative data analysis - an expanded sourcebook. SAGE.

Peša, I. 2017. Sawdust pellets, micro gasifying cook stoves and charcoal in urban Zambia: Understanding the value chain dynamics of improved stove initiatives. Netherlands: Leiden University.

Polanyi, M. 1958. Personal knowledge: Towards a post-critical philosophy. Chicago: University of Chicago Press.

Rehfuess, E.A., Puzzolo, E., Stanistreet, D., Pope, D. and Bruce, N.G. 2014. Enablers and barriers to large-scale uptake of improved solid fuel stoves: a systematic review. Environ Health Perspect. 122: 120-130. DOI: 10.1289/ehp.1306639

Republic of Zambia, 2019. National Energy Policy. Lusaka.

Rogers, E. 2003. Diffusion of Innovations, 5th Edition. New York, United States: Simon and Schuster.

Ruiz-Mercado, I., Masera, O., Zamora, H., Smith, K.R. 2011. Adoption and sustained use of improved cookstoves. Energy Policy 39: 7557-7566. https://doi.org/10.1016/j.enpol.2011.03.028

Seguin, R., Flax, V.L., Jagger, P. 2018. Barriers and facilitators to adoption and use of fuel pellets and improved cookstoves in urban Rwanda. PLOS ONE 13, https://doi.org/10.1371/journal.pone.0203775

Swedish Research Council. 2017. Good Research Practice. Stockholm, Sweden: Swedish Research Council.

United Nations. 2015. Transforming our world: The 2030 Agenda for sustainable development. New York: UN Publishing.

van Kleef, E., van Trijp, H. C. M., Luning, P. 2005. Consumer research in the early stages of new product development: A critical review of methods and techniques. Food Quality and Preference 16(3): 181-201.

https://doi.org/10.1016/j.foodqual.2004.05.012 